\title{
Peningkatan Profesionalisme Guru melalui Pelatihan Pengembangan Media Pembelajaran Sparkol Videoscribe di Kabupaten Malang
}

\author{
Saiful Amin ${ }^{1}$ \\ 1 Universitas Islam Negeri Maulana Malik Ibrahim Malang
}

\begin{abstract}
Article History ABSTRACT
Received 17.09.2019

Received in revised form 26.11.2019

Accepted 18.12.2019

Available online 30.12 .2019

ENHANCEMENT OF TEACHERS PROFESSIONALISM THROUGH SPARKOL VIDEOSCRIBE LEARNING MEDIA WORKSHOP IN MALANG DISTRICT. The program of activities proposed by the group of KKM 68 and 105 UIN Maulana Malik Ibrahim Malang, in the form of assistance in making sparkol videoscribe learning media. Through these activities, it is expected that the product of the development can add learning resources for teachers and students, and become an encouragement for students in learning. The method used in this service is service learning. Service learning is learning for students based on understanding and the process of recognizing a community. Community service activities in the form of ICT media development workshops can improve the understanding of elementary school teachers in Tulusbesar Village, Malang District in making and using learning media with sparkol videoscribe applications. The products produced in these activities are in the form of learning media in the form of sparkol videoscribe which are interesting in material grades 1 to 6 of elementary school. This service activity received a positive response from teachers as workshop participants.
\end{abstract}

KEYWORDS: Learning Media, Sparkol Videoscribe, Teachers Professionalism.

DOI: $10.30653 / 002.201944 .238$

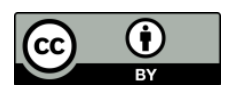

This is an open access article distributed under the terms of the Creative Commons Attribution 4.0 International License, which permits unrestricted use, distribution, and reproduction in any medium, provided the original work is properly cited. () 2019 Saiful Amin.

\section{PENDAHULUAN}

Kuliah Kerja Mahasiswa atau KKM UIN Mengabdi 2019 merupakan salah satu program Lembaga Penelitian dan Pengabdian kepada Masyarakat (LP2M), Universitas Islam Negeri Maulana Malik Ibrahim Malang yang bertujuan mengeksplorasi kemampuan mahasiswa dalam bentuk pengabdian kepada masyarakat (Tim LP2M, 2019). Dengan adanya program KKM, seorang mahasiswa diharuskan dapat mempraktekkan ilmu yang telah dipelajari di bangku kuliah terhadap kehidupan masyarakat. Sebab, semua peran mahasiswa dari berbagai jurusan akan diperlukan di masyarakat. Maka dari

${ }^{1}$ Corresponding author: Jurusan Pendidikan IPS, FITK, Universitas Islam Negeri Maulana Malik Ibrahim Malang; Jl. Gajayana No. 50 Malang. Email: amin.geo87@pips.uin-malang.ac.id 
itu, untuk dapat memanfaatkan semua kemampuan masing-masing kelompok yang sesuai dengan kebutuhan masyarakat desa, sehingga perlu disusun beberapa program kegiatan yang didasarkan kepada hasil survei permasalahan di lapangan.

Berdasarkan hasil obsevasi dan wawancara di SDN 1 dan SDN 2 Tulusbesar, didapatkan fakta tentang kurang maksimalnya pemanfaatan media berbasis teknologi yang mendukung penyampaian informasi dari guru kepada siswa saat pengajaran berlangsung. Guru lebih sering menggunakan metode ceramah dan tanya jawab singkat pada saat pembelajaran yang kemudian dilanjutkan dengan penugasan sesuai buku teks. Sehingga, siswa merasa bosan dengan pembelajaran di kelas, sehingga minat belajar siswa menjadi rendah.

Berdasarkan kondisi pembelajaran tersebut, maka kelompok KKM 68 dan 105 UIN Maulana Malik Ibrahim Malang, membuat sebuah program pendampingan kepada guruguru SD di Desa Tulusbesar untuk workshop pembuatan media pembelajaran. Program pendampingan ini bertujuan agar guru-guru SD di Desa Tulusbesar dapat membuat media pembelajaran yang menarik dan dapat diterapkan di kelas, sehingga siswa menjadi lebih tertarik dalam mengikuti kegiatan belajar.

Media pembelajaran yang notabene merupakan alat bantu perantara dalam penyampaian materi guna memaksimalkan peran pendidikan, tentu dalam pemilihannya harus turut diperhatikan. Hal tersebut mengingat pemilihan media pembelajaran yang tepat, dapat turut mempengaruhi kemaksimalan peran media pembelajaran dalam pencapaian tujuan. Penggunaan media pembelajaran yang sesuai dengan karakeristik kebutuhan siswa dan materi yang hendak disampaikan, akan turut membantu membangkitkan rasa ingin tahu dan motivasi siswa (Alannasir, 2016), serta sebagai alat bantu stimulus dalam kegiatan pembelajaran, serta memberikan pengaruh psikologis kepada siswa (Rusman, 2017).

Media pembelajaran merupakan salah satu komponen sumber balajar bagi siswa. Guru harus mampu memiih media pembelajaran sesuai dengan tujuan belajar, serta siswa dapat menerima media tersebut dengan baik sebagai sumber belajar (Oka, 2017). Motivasi siswa yang rendah dalam pembelajaran, dapat disebabkan oleh kurangnya kreativitas guru dalam menyiapkan media pembelajaran (Kurnia \& Nugroho, 2017). Rendahnya motivasi dalam belajar ini akan memicu hasil belajar siswa yang kurang memuaskan. Guru rata-rata masih menggunakan ceramah pada saat menyampaikan pelajaran. Terdapat anggapan bahwa ceramah merupakan metode yang mudah dilaksanakan. Padahal penggunaan metode ceramah kurang menghadapkan siswa kepada hal-hal yang konkret.

Permasalahan yang terjadi bahwa penggunaan media belum membudaya untuk diterapkan di dalam kelas, sehingga siswa mengalami kesulitan dalam memahami materi pelajaran (Sriyanto, Murniawaty, Nuryana, \& Ismiyati, 2018). Namun, pemilihan media yang kurang kreatif juga membuat siswa kurang antusias dan kurang berminat dalam mengikuti pembelajaran (Umbara, Rosyid, \& Setiawan, 2019). Di era milenial ini, sebaiknya media pembelajaran dikembangkan dengan teknologi informasi. Hal ini sebagai upaya penyeimbangan terhadap generasi sekarang yang tergolong sebagai generasi digital native, dimana generasi sekarang lebih nyaman menggunakan peralatan digital (Arsyad, 2014). 
Video merupakan salah satu media pembelajaran berbasis digital yang cukup terkenal di kalangan generasi sekarang. Media video memiliki kemudahan dalam penggunaannya dan mampu memberikan kemudahan belajar dalam bentuk visual maupun audio sehingga dapat memfasilitasi karakteristik belajar yang berbeda-beda hanya dengan satu media (Husain, 2014). Menurut Koumi (Marsitin, Sesanti, \& Agustina, 2019) video dapat merangsang keinginan belajar dan memberi motivasi untuk keberhasilan belajar. Hal ini membuat video menjadi pilihan tepat sebagai media untuk meningkatkan minat siswa SD Tulusbesar dalam belajar.

Program kegiatan yang diusulkan oleh kelompok KKM 68 dan 105 UIN Maulana Malik Ibrahim Malang, berupa pendampingan dalam pembuatan media pembelajaran sparkol videoscribe. Media pembelajaran dengan sparkol videoscribe merupakan salah satu media animasi yang merangkai gambar menjadi video utuh (Silmi \& Rachmadyanti, 2018). Media pembelajaran ini menyajikan materi dengan memadukan gambar, grafis, suara, dan desain yang menarik. Hal ini akan membuat siswa SD menjadi mudah dalam menerima pelajaran di kelas. Melalui kegiatan pendampingan workshop pembuatan media pembelajaran sparkol videoscribe ini, diharapkan produk hasil pengembangan dapat menambah sumber belajar bagi guru dan siswa, serta menjadi penyemangat siswa-siswa SD di Desa Tulusbesar dalam belajar.

\section{METODE PELAKSANAAN}

Kegiatan pengabdian ini menggunakan metode service learning. Service learning merupakan pembelajaran bagi mahasiswa yang didasari oleh pemahaman dan proses mengenali suatu komunitas (Nusanti, 2014). Komunitas yang dimaksud adalah guruguru sekolah dasar sebagai peserta pelatihan. Terdapat beberapa komponen penting dari service learning dan hubungan antara komponen tersebut menunjukkan karakteristik dari model ini. Komponen-komponen tersebut adalah materi akademik, pengabdian masyarakat yang relevan, dan refleksi kritis (Lucas, 2011).

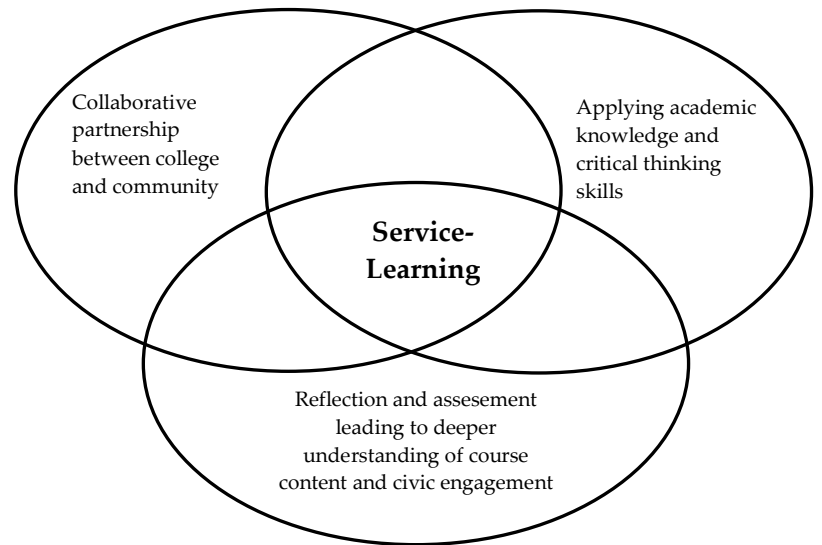

Gambar 1. Komponen Model Service Learning Sumber: Lucas (2011)

Service-learning merupakan kombinasi antara materi akademik dan pengabdian masyarakat. Kedua materi tersebut harus saling berkaitan, sehingga siswa dapat memberikan pelayanan kepada masyarakat dengan pengalaman akademik yang didapat di kelas. 
Refleksi dalam service learning menghubungkan antara materi akademik (teori) dan pengalaman selama pengabdian masayarakat (praktek). Oleh karena itu, melalui pengalaman mereka, siswa dapat meningkatkan kualitas pembelajaran dan pengabdian.

Service learning merupakan strategi pembelajaran kolaboratif, sehingga harus ada kerja sama (kemitraan) antara universitas dan masyarakat. Kemitraan (partnership) ini dapat mempromosikan peningkatan akademik, perkembangan personal, dan keterlibatan dalam masyarakat bagi siswa.

Service learning merupakan salah satu bentuk implementasi dari experiential learning (Jenkins \& Sheehey, 2009). Hal ini akan bermakna bagi mahasiswa peserta KKM bahwa pembelajaran sebenarnya terjadi jika mereka secara aktif mengkonstruksi makna melalui pengalaman nyata yang terbimbing, sehingga memungkinkan mereka mengembangkan kompetensi berpikir kritis melalui refleksi, dan pada saat yang sama mereka dapat berkontribusi kepada masyarakat sebagai perwujudan tugas kemasyarakatan mereka.

Langkah-langkah kegiatan dalam pengabdian ini adalah sebagai berikut.

1) Kerangka Pemecahan Masalah

Memberikan pelatihan dan peningkatan kemampuan guru-guru sekolah dasar dalam pembuatan media pembelajaran sparkol videoscribe. Pengabdian ini menggunakan praktikum secara langsung dan ceramah.

2) Realisasi Pelaksanaan Kegiatan

Sebelum dimulai kegiatan pelatihan pembuatan media pembelajaran sparkol videoscribe, diawali dengan presentasi tentang konsep media pembelajaran ICT oleh dosen pembimbing lapangan (DPL). Selanjutnya pengenalan tentang media pembelajaran sparkol videoscribe oleh mahasiswa kepada masyarakat (guru sekolah dasar sebagai peserta pelatihan). Pengenalan ini digunakan untuk membantu peserta dalam pembuatan media pembelajaran sparkol videoscribe.

Pihak yang terlibat dalam kegiatan pelatihan ini adalah guru-guru sekolah dasar di Desa Tulusbesar sebagai peserta pelatihan, yang berasal dari SDN 1 Tulusbesar dan SDN 2 Tulusbesar. Dosen pendamping lapangan sebagai pemateri workshop tentang media pembelajaran berbasis ICT. Selanjutnya, mahasiswa peserta KKM UIN Maulana Malik Ibrahim Malang dari kelompok 68 dan 105, sebagai pemateri dalam pelatihan pembuatan media pembelajaran sparkol videoscribe. Kegiatan pelatihan ini bertempat di SD Negeri 02 Tulusbesar, Kecamatan Tumpang, Kabupaten Malang.

Pengabdian ini dilaksanakan pada Hari Sabtu, tanggal 19 Januari 2019. Kegiatan dilakukan dalam 1 (satu) hari, yaitu dimulai pukul 08.00 WIB dengan durasi pelatihan \pm 4 (empat) jam, terdiri dari:

60 menit penjelasan umum media pembelajaran ICT.

30 menit pengenalan media pembelajaran sparkol videoscribe.

120 menit pelatihan pembuatan media pembelajaran sparkol videoscribe.

30 menit untuk evaluasi keseluruhan pelatihan.

Luaran yang dihasilkan adalah kemampuan peserta dalam membuat dan menggunakan media pembelajaran sparkol videoscribe. Melalui pelatihan ini, diharapkan guru-guru (sebagai peserta) dapat memanfaatkan dan menerapkan sparkol videoscribe 
sebagai media pembelajaran di kelas, agar motivasi dan minat belajar siswa menjadi meningkat.

\section{HASIL DAN PEMBAHASAN}

Kegiatan pengabdian workshop pembuatan media pembelajaran berbasis ICT ini melalui beberapa proses, yaitu sebagai berikut.

\section{Penetapan Media Pembelajaran}

Workshop pembuatan media pembelajaran berbasis ICT ini menetapkan sparkol videoscribe sebagai materi pelatihan. Pemilihan media pembelajaran sparkol videoscribe ini didasarkan pada hasil observasi mahasiswa KKM di sekolah dasar Desa Tulusbesar. Hasil observasi menunjukkan bahwa perlu adanya pembaruan dalam pembelajaran, terutama dalam penggunaan media ICT. Media pembelajaran ICT sparkol videoscribe dianggap cocok untuk dilakukan pelatihan kepada guru-guru di sekolah dasar Desa Tulusbesar karena sebagian besar guru-guru belum banyak menggunakan media pembelajaran berbasis ICT. Selain itu, dengan karakteristik siswa yang terlihat tidak antusias saat pembelajaran, maka dengan penggunaan media sparkol videoscribe diindikasikan pembelajaran akan menjadi menarik.

\section{Penetapan Peserta dan Sekolah Sebagai Mitra}

Sekolah yang terpilih sebagai tempat workshop pembuatan media pembelajaran sparkol videoscribe adalah SD Negeri Tulusbesar 2, Kecamatan Tumpang. Peserta workshop terdiri dari guru-guru sekolah dasar di Desa Tulusbesar. Terdapat 3 (tiga) sekolah dasar di Desa Tulusbesar, yaitu dijelaskan pada tabel berikut.

Tabel 1. Sebaran Jumlah Guru dan Sekolah Dasar Desa Tulusbesar

\begin{tabular}{llll}
\hline No. & Nama Sekolah & Status & Jumlah Guru \\
\hline 1. & SD Negeri Tulusbesar 1 & Negeri & 10 \\
2. & SD Negeri Tulusbesar 1 & Negeri & 8 \\
3. & SD Muhammadiyah 3 Tumpang & Swasta & 10 \\
\hline Jumlah & & 28 \\
\hline
\end{tabular}

Sumber: Kemdikbud, 2019

Berdasarkan Tabel 1, terdapat 28 guru sekolah dasar di Desa Tulusbesar, dengan rincian dari SD Negeri Tulusbesar 1 sebanyak 10 guru, SD Negeri Tulusbesar 2 sebanyak 8 guru, dan SD Muhammadiyah 3 Tumpang sebanyak 10 guru. Peserta workshop berjumlah 18 orang yang diambil 6 guru dari masing-masing sekolah dasar di Desa Tulusbesar.

\section{Pelaksanaan Workshop Media Pembelajaran}

Kegiatan pelatihan pembuatan media pembelajaran sparkol videoscribe dengan materi yang meliputi: penyampaian pentingnya media pembelajaran berbasis ICT di era milenial, gambaran umum sparkol videoscribe sebagai media pembelajaran yang menarik, serta langkah-langkah dalam membuat media pembelajaran sparkol videoscribe. Selanjutnya memberikan motivasi agar guru lebih kreatif dalam membuat media pembelajaran yang lain. Ketercapai kegiatan pengabdian ini, yaitu hasil media 
pembelajaran sparkol videoscribe yang dibuat oleh guru sekolah dasar di Desa Tulusbesar, Kecamatan Tumpang.

Kegiatan seminar dengan materi media pembelajaran berbasis ICT disampaikan oleh dosen pendamping KKM kelompok 68 dan 105 sendiri, yaitu Bapak Saiful Amin, M,Pd. Kegiatan seminar ini berangsung 120 menit, dengan rincian 60 menit penjelasan umum tentang pentingnya media berbasis ICT di era milenial dan 30 menit tentang jenis-jenis media pembelajaran ICT yang di dalamnya mengulas tentang media sparkol videoscribe. Pelaksanaan penjelasan tentang media pembelajaran ICT oleh dosen pendamping KKM seperti pada Gambar 2.

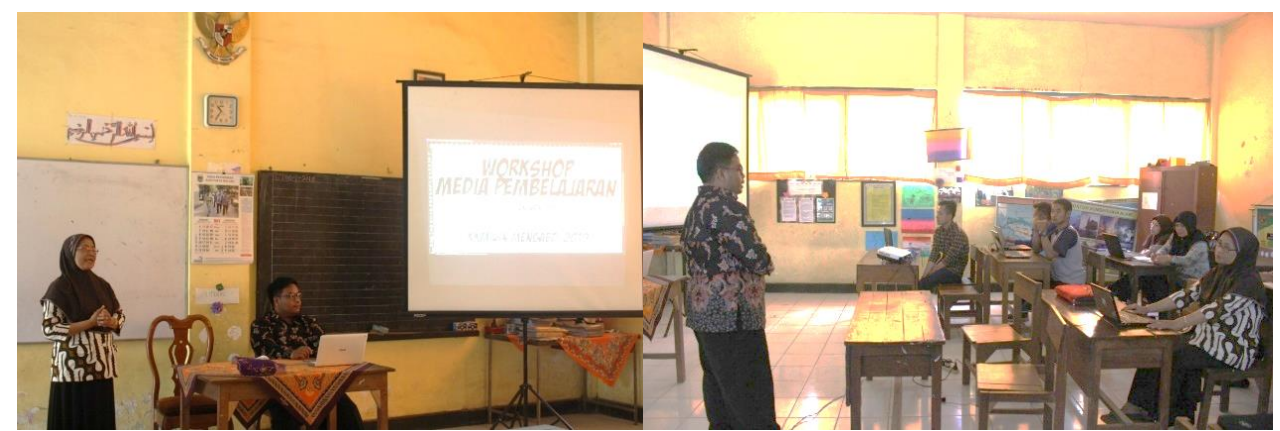

Gambar 2. Sambutan Kepala SDN Tulusbesar 2 dan Penjelasan Media Pembelajaran oleh DPL

Kegiatan selanjutnya adalah pelatihan pembuatan media pembelajaran sparkol videoscribe. Pembuatan media sparkol videoscribe dengan materi meliputi: penjelasan umum sparkol videoscribe sebagai media pembelajaran yang menarik, memberikan pendampingan dalam menginstal aplikasi program sparkol videoscribe, serta langkahlangkah menggunakan program sparkol videoscribe. Penjelasan umum sparkol videoscribe disampaikan oleh salah satu mahasiswa KKM, yaitu Muhammad Faizur Rohman.

Selanjutnya, pembuatan media sparkol videoscribe didampingi oleh mahasiswa KKM 68 dan 105 yang terlibat sebagai panitia penyelenggara workshop. Pendampingan workshop oleh mahasiswa dapat menjadikan proses belajar menjadi lebih interaktif. Mahasiswa dapat menerapkan pelajaran yang didapatkan di bangku kuliah kepada masyarakat, sehingga kemampuan bisa dibangun dan dikembangkan lebih luas. Kegiatan pengabdian dengan workshop dan praktik menjadikan mahasiswa lebih interaktif dan mengkonstruk kemampuannya (Zuriah, Sunaryo, \& Yusuf, 2016).

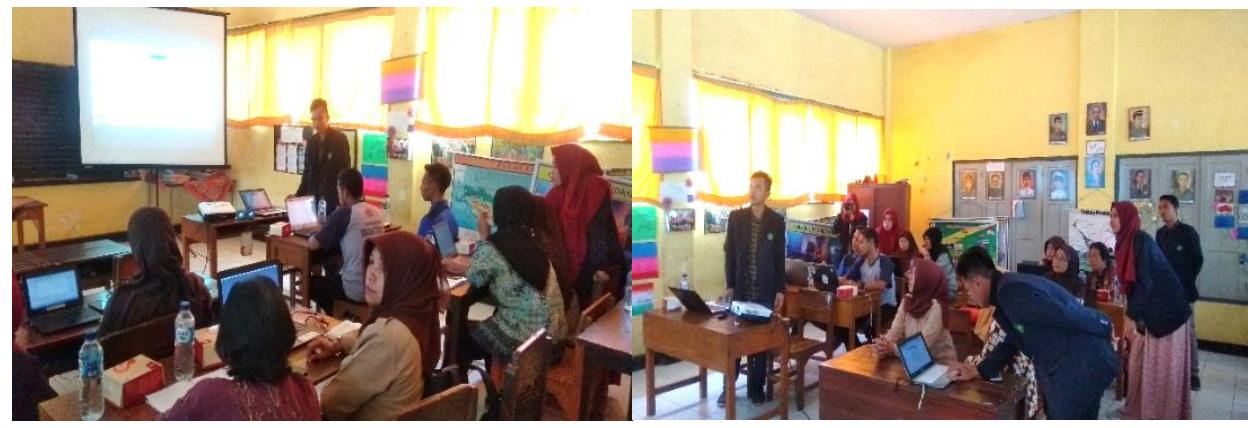

Gambar 3. Penjelasan Sparkol Videoscribe dan Pendampingan oleh Mahasiswa KKM

Berkenaan dengan produk workshop maka guru sekolah dasar di Desa Tulusbesar diharapkan kreatif dalam membuat media pembelajaran sparkol videoscribe agar menarik 
bagi siswa saat pembelajaran di kelas. Oleh karena itu, pelatihan dengan memanfaatkan teknologi informasi menjadi penting, agar memotivasi guru dalam membuat media pembelajaran berbasis ICT (Husain, 2014).

Hasil yang dicapai dalam pelaksanaan program pengabdian masyarakat pada workshop pengembangan media pembelajaran untuk guru-guru sekolah dasar di Desa Tulusbesar, yaitu pemahaman dalam membuat media pembelajaran berbasis ICT yang menarik melalui program sparkol videoscribe. Guru-guru peserta workshop sangat antusias dalam mengikuti pelatihan pembuatan media sparkol videoscribe ini. Peserta menganggap bahwa ini adalah hal baru dalam meningkatkan pembelajaran di kelas melalui pembaruan media pembelajaran, karena selama ini guru-guru hanya menjelaskan materi pelajaran dengan media seadanya. Selain itu, hasil pelatihan menunjukkan bahwa ternyata guruguru sekolah dasar memiliki kreativitas dalam membuat media sparkol videoscribe. Hal ini tampak pada hasil pembuatan media pembelajaran sparkol videoscribe yang pada Gambar 4 dan Gambar 5.

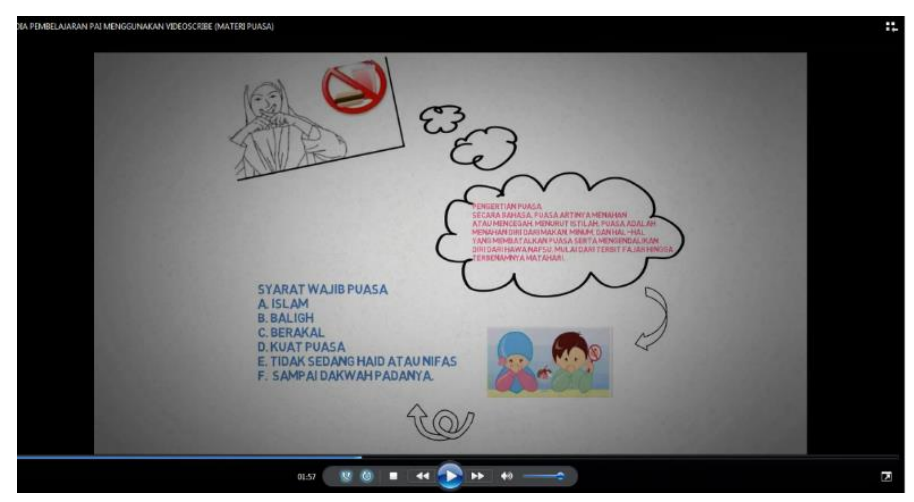

Gambar 4. Contoh Hasil Media Sparkol Videoscribe Materi PAI

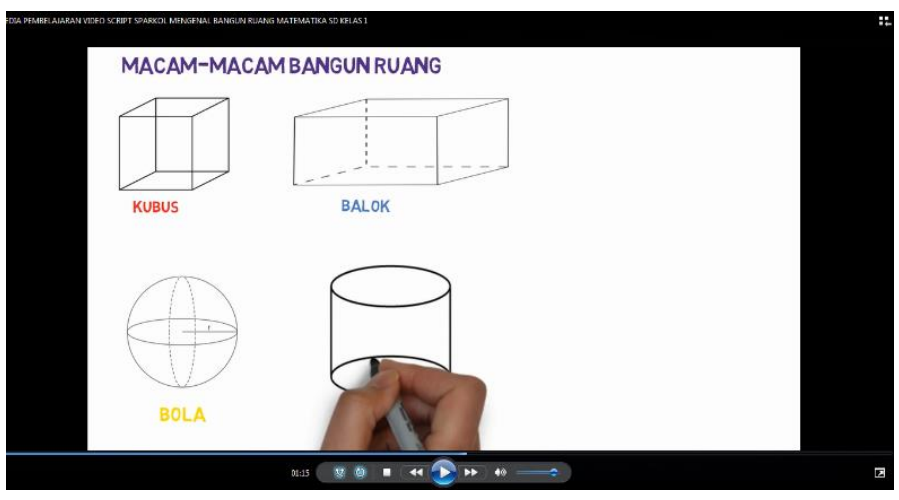

Gambar 5. Contoh Hasil Media Sparkol Videoscribe Materi Matematika

Ketercapaian pemahaman guru sekolah dasar di Desa Tulusbesar dalam pembuatan media pembelajaran berbasis ICT, diharapkan berpengaruh terhadap peningkatan kualitas guru dalam pembelajaran. Guru harus kreatif dalam pembelajaran terutama penggunaan media pembelajaran, baik berbasis ICT maupun Non-ICT, agar tujuan pembelajaran dapat tercapai secara maksimal. Hasil workshop juga menunjukkan bahwa respon yang positif pada pelaksanaan desiminasi hasil pembuatan media pembelajaran. Respon tanggapan yang positif dari guru-guru sekolah dasar di Desa Tulusbesar sebagai 
peserta, sangat membatu dalam suksesnya kegiatan program pengabdian masyarakat yang dilakukan oleh KKM kelompok 68 dan 105 UIN Maulana Malik Ibrahim Malang ini.

Pembuatan media pembelajaran berbasis ICT, yaitu sparkol videoscribe merupakan salah satu keterampilan guru dalam menggunakan teknologi. Pembelajaran dengan menggunakan teknologi sangat berperan dalam upaya meningkatkan kualitas pendidikan (Umbara, Rosyid, \& Setiawan, 2019). Guru sebagai tenaga pendidik harus melakukan inovasi dalam pembelajaran (Murniawaty \& Nuryana, 2018). Guru harus mampu memperbaharui kompetensi dan pengetahuannya dalam bidang teknologi informasi di era revolusi 4.0 (Munir, 2009).

Hasil media pembelajaran dengan sparkol videoscribe yang dihasilkan guru-guru peserta workshop di Desa Tulusbesar sangat bermanfaat dalam meningkatkan pembelajaran di kelas. Siswa yang belajar dengan menggunakan media sparkol videoscribe lebih efektif dalam belajarnya, karena pusat perhatian siswa tertuju kepada media tersebut (Silmi \& Rachmadyanti, 2018). Hal ini akan memicu hasil belajar siswa yang meningkat.

Pelaksanaan workshop media pembelajaran memberikan catatan penting baik bagi guru dan tim pengabdi, pertama terkait pemahaman para guru mengenai sparkol videoscribe. Pada awal pelatihan, guru masih merasa kesulitan dalam menginstal dan mengoperasikan program. Hal ini memberikan gambaran bahwa banyak guru yang belum menguasai teknologi IT dan jarang menerapkan media berbasis ICT dalam pembelajaran di kelas.

Kedua, keterbatasan waktu pelatihan merupakan masalah bagi guru sebagai peserta, karena waktu lebih banyak digunakan untuk menginstal aplikasi sparkol videoscribe. Para guru mengeluhkan bahwa pada materi inti pembuatan media, waktu terasa sangat singkat. Mereka banyak yang belum menyelesaikan dengan tuntas. Selain itu, karena media sparkol videoscribe merupakan hal baru bagi guru, mereka sangat antusias dalam mengikuti pelatihan. Materi-materi di sekolah dasar bisa menjadi menarik untuk disampaikan kepada siswa sekolah dasar, karena dengan media sparkol videoscribe guru dapat menambahkan gambar-gambar agar siswa fokus dalam pembelajaran di kelas.

Kegiatan pengabdian berupa workshop pembuatan media pembelajaran ini memberikan kontribusi kepada guru, baik itu perubahan pada tingkat kepahaman mengenai pembuatan media sparkol videoscribe, maupun pada paradigma berpikir dan sangat memotivasi para guru untuk mengembangkan media pembelajaran berbasis ICT yang menarik. Selain guru, kegiatan ini sangat bermanfaat bagi mahasiswa KKM sendiri dalam belajar mengabdikan diri di masyarakat sebelum mereka lulus dari bangku kuliah. Mahasiswa mampu menerapkan ilmu yang didapat dan dapat mengembangkan keilmuannya dalam masyarakat.

\section{SIMPULAN}

Kegiatan pengabdian masyarakat oleh KKM kelompok 68 dan 105 UIN Maulana Malik Ibrahim Malang, berupa workshop pengembangan media ICT dapat meningkatkan pemahaman guru-guru sekolah dasar di Desa Tulusbesar dalam membuat dan menggunakan media pembelajaran dengan aplikasi sparkol videoscribe. Produk yang dihasilkan dalam kegiatan tersebut berupa media pembelajaran dalam bentuk sparkol 
videoscribe yang menarik pada materi kelas 1 sampai 6 sekolah dasar. Kegiatan pengabdian ini mendapatkan respon yang positif dari guru sebagai peserta workshop. Seperti yang diutarakan oleh salah satu guru peserta kegiatan, bahwa kegiatan pelatihan pembuatan media pembelajaran ini begitu diharapkan oleh mereka, karena guru-guru membutuhkan penyegaran ilmu terutama yang berbasis teknologi informasi.

Saran yang dapat diberikan oleh tim pelaksana pengabdian demi peningkatan kualitas kegiatan pelatihan adalah sebagai berikut: 1) Pelatihan sejenis hendaknya dilakukan secara keberlanjutan, agar keterjangkauan informasi tentang media pembelajaran berbasis ICT menjadi lebih luas mengingat teknologi menjadi sangat penting di jaman Revolusi Industri 4.0 ini; 2) Waktu dalam pelaksanaan workshop perlu ditambah lebih lama lagi, mengingat guru-guru harus beradaptasi lagi dengan teknologi yang baru; dan 3) Untuk Dinas Pendidikan terkait, perlu adanya kegiatan lanjutan yang lebih mampu mengakomodir mereka untuk mengembangkan keprofesionalan guru dalam hal pengembangan media pembelajaran.

\section{REFERENSI}

Alannasir, W. (2016). Pengaruh penggunaan media animasi dalam pembelajaran IPS terhadap motivasi belajar siswa kelas IV SD Negeri Mannuruki. Journal of EST (Educational Science and Technology), 2(2), 81-90. https://doi.org/10.26858/est.v2i2.2561

Arsyad, A. (2014). Media pembelajaran. Jakarta: Raja Grafindo Persada.

Husain, C. (2014). Pemanfaatan teknologi informasi dan komunikasi dalam pembelajaran di SMA Muhammadiyah Tarakan. Jurnal Kebijakan dan Pengembangan Pendidikan, 2(2), 184-192.

Jenkins, A., \& Sheehey, P. (2009). Implementing service learning in special education coursework: What We learned. Education, 129(4), 668-682.

Kurnia, E. D., \& Nugroho, Y. E. (2017). Pelatihan pembuatan media pembelajaran aksara Jawa Bagi Guru Bahasa Jawa SMA di Kabupaten Rembang. Jurnal Pengabdian Pada Masyarakat, 2(2), 101-112. https://doi.org/10.30653/002.201722.22

Lucas, D. J. (2011). The effects of a service learning introductory course in diversity on pre-service teachers attitudes' toward teaching diverse students. Lynchburg, VA: Liberty University.

Marsitin, R., Sesanti, N. R., \& Agustina, R. (2019). Pelatihan IT melalui pembuatan e-modul matematika bagi guru matematika SMK Kabupaten Malang. Jurnal ABDIMAS Unmer Malang, 3, 1-6.

Munir. (2009). Kontribusi teknologi informasi dan komunikasi (TIK) dalam pendidikan di era globalisasi pendidikan Indonesia. Jurnal Pendidikan Teknologi Informasi dan Komunikasi (PTIK), 2(2), 1-4. 
Murniawaty, I., \& Nuryana, I. (2018). Peningkatan profesionalisme guru ekonomi dalam pembelajaran di SMA Kabupaten Semarang. Jurnal Pengabdian Dan Pemberdayaan Masyarakat UMP, 2(2), 357-362.

Nusanti, I. (2014). Strategi service learning sebuah kajian untuk mengembangkan kegiatan pembelajaran. Jurnal Pendidikan dan Kebudayaan, 20(2), 251-260. https://doi.org/10.24832/jpnk.v20i2.142

Oka, G. P. A. (2017). Media dan multimedia pembelajaran. Yogyakarta: Budi Utama.

Rusman. (2017). Berorientasi standar proses pendidikan. Jakarta: Prenadamedia Group.

Silmi, M. Q., \& Rachmadyanti, P. (2018). Pengembangan media pembelajaran video animasi berbasis sparkol videoscribe tentang persiapan kemerdekaan RI SD kelas V. Jurnal Penelitian Pendidikan Guru Sekolah Dasar, 6(4), 486-495.

Sriyanto., Murniawaty, I., Nuryana, I., \& Ismiyati. (2018). Peningkatan Profesionalisme Guru Ekonomi Dalam Pembelajaran Di SMA Kabupaten Semarang. Jurnal Pengabdian Dan Pemberdayaan Masyarakat UMP, 2(2), 357-362.

Tim LP2M. (2019). Pedoman teknis kuliah kerja mahasiswa (KKM) UIN Mengabdi 2019. Malang: UIN Malang.

Umbara, U., Rosyid, A., \& Setiawan, D. L. (2019). Pelatihan pembuatan media pembelajaran matematika berbasis flash menggunakan adobe animate bagi guru SMP di Kabupaten Kuningan. Jurnal Pengabdian Pada Masyarakat, 4(1), 93-104. https://doi.org/10.30653/002.201941.84

Zuriah, N., Sunaryo, H., \& Yusuf, N. (2016). Guru dalam pengembangan bahan ajar kreatif inovatif berbasis potensi lokal. Jurnal Dedikasi, 13, 39-49. 